\title{
Study of T1 Copper Corrosion Behavior in Qingyuan Rural Atmosphere
}

\author{
Yongcun Liang ${ }^{1}$, Fan Yang ${ }^{2}$, Yinjie Kuang ${ }^{2}$
}

${ }^{1}$ Guangdong Power Grid Co., Ltd. Electric Power Research Institute metals Guangzhou 510080, China

${ }^{2}$ Chemical and Biological Engineering, Changsha University, Changsha 410114

hunter2011@foxmail.com

Keywords: Copper; Atmospheric Corrosion; Qingyuan; Electrochemical Impedance Spectroscopy

\begin{abstract}
By optical microscopy, SEM, XRD, EDS and EIS, study the corrosion behavior of copper in Qingyuan rural atmospheric environment. The results showed that: after exposure in Qingyuan rural atmosphere, copper has corrosion. With time, the corrosion products increased, and gradually cover the surface of the copper layer to form a more compact, resulting in corrosion rate decreases. In the first six months of exposure, copper corrosion products are mainly $\mathrm{Cu}_{2} \mathrm{O}$, over time, the impact of other atmospheric pollutants on corrosion of copper increase, 12 months later, the corrosion products appeared are mainly $\mathrm{CuOHCl}$ and $\mathrm{CuS}$.
\end{abstract}

\section{Introduction}

Copper is an important power transmission material more sensitive to air pollution, the corrosion behavior of pollutants in the atmosphere type, relative humidity and temperature and other factors related to [1]. Currently, research on copper corrosion in marine atmosphere and industrial pollution in the atmosphere have been many reports [2-8], but the corrosion of Copper fewer pollutants rural atmosphere but rarely reported. In order to fully understand the different atmosphere corrosion of copper, it is necessary to study the atmospheric corrosion behavior of copper in a rural environment. This working in field exposure was studied in Qingyuan atmosphere, after the corrosion behavior of different exposure times T1 copper.

\section{Test Method}

Experimental materials: T1 copper, chemical composition of $\mathrm{Cu}>99.95$ (mass percentage). Accurate to $1 \mathrm{mg}$ after exposure to atmospheric corrosion tests with sample size of $150 \mathrm{~mm} \times 100$ $\mathrm{mm} \times 1 \mathrm{~mm}$, the test piece surface cleaning grease with acetone and ethanol and dried, placed in the dryer after 24h standby weighing, weighing .

Exposure experiment venue is Guangdong Qingyuan 110KV substation Li River, according to GB/T 146545-2008 execution. Referring to GB/T 16545-1996 The method of removing the sample surface corrosion product, which uses $\mathrm{H} 2 \mathrm{O}: \mathrm{HCl}=2: 1$ (volume ratio) solution soak 1-3min rust, corrosion weight loss averaged three samples value. Electrochemical impedance rusted sample spectroscopy (EIS) by CHI660D electrochemical workstation test, using a three-electrode system, the electrolyte is $0.1 \mathrm{~mol} / \mathrm{L} \mathrm{Na} 2 \mathrm{SO} 4$ solution to a saturated calomel electrode as the reference electrode, a platinum electrode than as an auxiliary electrode, the size of the working electrode was $10 \mathrm{~mm} \times 10 \mathrm{~mm}$. AC impedance tests carried out in the open circuit potential, the frequency range of $100000 \mathrm{~Hz} \sim 0.01 \mathrm{~Hz}$, the amplitude of the sine wave excitation signal is $5 \mathrm{mV}$.

\section{Experimental Results and Discussion}

May copper corrosion rate exposure at different times after the change of atmosphere in Qingyuan curve is shown in Figure 1. It can be seen: With the prolonged exposure time, the corrosion rate of copper is reduced. When 9 and 12 months exposure, the corrosion rate of copper tends to be stable, at this time may be a copper surface has been completely covered with a layer of relatively dense due to corrosion products. To further understand the atmospheric corrosion of 
copper, we observed by optical microscope morphology of the copper surface after different exposure times, the results shown in Figure 2. Figures 2A-E is a magnification of 100, 200 of FIG. 2F magnification. A month after exposure to copper, the surface of some green corrosion products adhere, there has been a small amount of local pitting, most areas can still see the purple copper substrate (Fig. 2A); with prolonged exposure time, the copper surface is more An increasing number of corrosion products covered copper purple gradually disappear (Figure 2B-E), after the enlarged Fig. 3E, found that the surface there are some pits of various sizes (Fig. 2F).

We also investigated by scanning electron microscope copper after 1,6 and 12 months of exposure, the morphology of corrosion products, results shown in Figure 3. After a month of copper exposure, only a small amount of irregular lumps or granular corrosion products scattered in the copper surface (Fig. 3A), the overall corrosion lighter; when the exposure time was extended to six months, the corrosion of copper increased, the surface showed a large number of crack-like corrosion product, these massive corrosion products on the substrate adhesion is not continuous, can not form a dense layer (Fig. 3B); thereafter, with prolonged exposure time to 12 months, the copper surface the gradual accumulation of corrosion products, thickening, plus the role of environmental factors, the original massive corrosion products became smaller and link together to form a lamellar structure becomes more compact (Fig. 3).

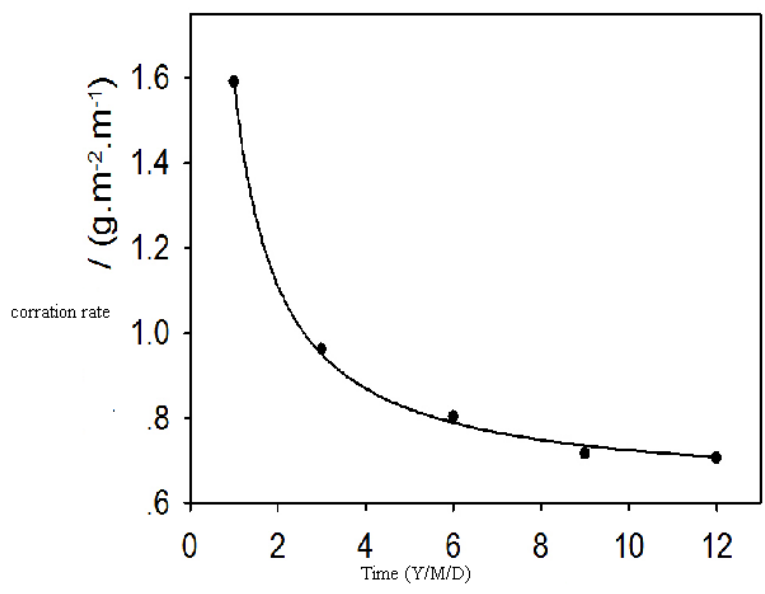

Fig. 1 Copper corrosion rate of change curve

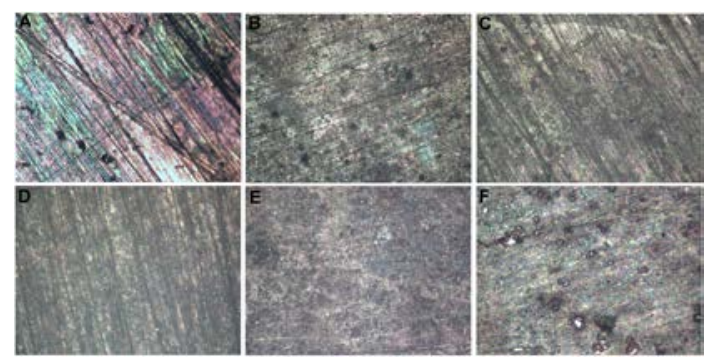

Fig. 2 Different times after exposure to copper metallurgical micrographs. A: 1 month; B: 3 months; C: 6 months; D: 9 months;
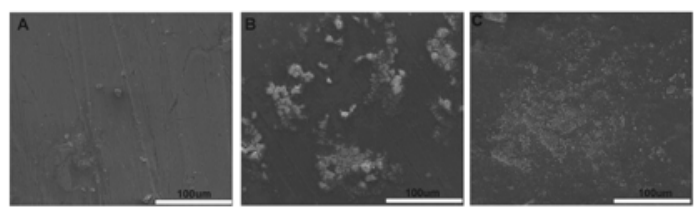

Fig. 3 Scanning electron micrograph of copper at different times after exposure. A: 1 month; B: 6 months; C: 12 months 


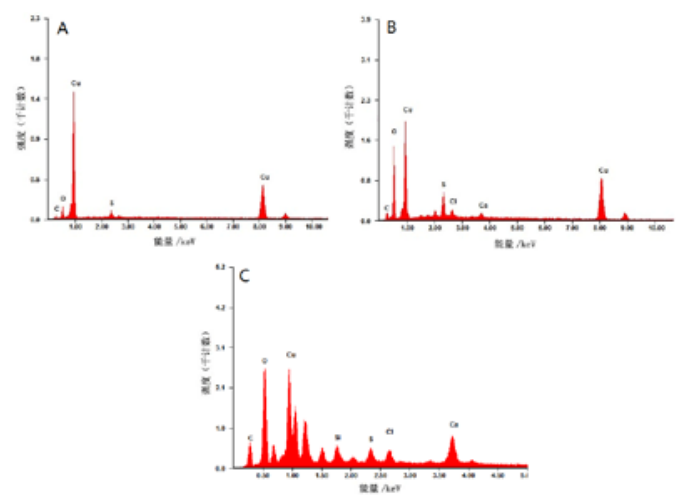

Fig. 4 Copper at different times after exposure EDS FIG. A: 3 months; B: 6 months; C: 12 months

We are exposed to 3, 6 and 12 months in Qingyuan copper atmosphere EDS spectrum analysis were carried out, the results shown in Figure 4. As can be seen, along with prolonged exposure time, the atmospheric oxygen to copper corrosion significantly strengthened, EDS EDS figure O peak intensity increased significantly, increasing the oxygen content of corrosion products; 12 months after exposure, red copper corrosion product also contains $\mathrm{S}, \mathrm{Cl}, \mathrm{Si}, \mathrm{Ca}$ and other elements, including $\mathrm{S}, \mathrm{Cl}$ from atmospheric contaminants such as sulfide and chloride ions corrosion of copper, $\mathrm{Si}$, Ca are from the copper surface adsorption of dust and gravel (the main component of $\mathrm{CaCO} 3$ and $\mathrm{SiO} 2$, etc.).

To further understand the composition of the corrosion products, but also for 3, 6 and 12 months of exposure in Qingyuan copper atmosphere XRD tests were carried out, the results shown in Figure 5. 5A and 5B, four diffraction peaks at $2 \theta$ angle 43.35, 50.44, 74.14, 89.91 degrees are characteristic peak copper substrate. 3 months after exposure, XRD spectra near 36.44 degrees appears only one attributed to $\mathrm{Cu} 2 \mathrm{O}$, less intense diffraction peaks, indicating that although the corrosion products of copper oxide-based, but the overall amount is too small; when exposed to prolonged six months later, the diffraction peak intensity near 36.44 degrees increased significantly, also appeared in three other locations belonging to $\mathrm{Cu} 2 \mathrm{O}$ characteristic diffraction peaks in Qingyuan atmospheric exposure after six months showed copper corrosion product is mainly Cu2O. After 12 months of exposure, XRD spectra is difficult to see attributed to copper and copper oxide diffraction peaks, only a few low intensity diffraction peaks, when copper long-term exposure to the atmosphere, it is easy to corrosion of copper surface adsorption The dust in the atmosphere to form a dense film, influence of X-rays to penetrate. After comparative analysis and XRD standard spectra, we find $2 \theta$ angle of 15.01 and 28.68 of the diffraction peaks were relatively close and $\mathrm{CuOHCl}$ and $\mathrm{CuS}$ spectra, the presence of these two substances can be considered corrosion products, they are further and $\mathrm{Cu} 2 \mathrm{O}$ the atmosphere caused by chloride ions and sulfide reaction. Combined EDS data can be judged exposed copper corrosion product 12 months after the atmosphere in Qingyuan mainly $\mathrm{Cu} 2 \mathrm{O}, \mathrm{CuOHCl}$ and $\mathrm{CuS}$.
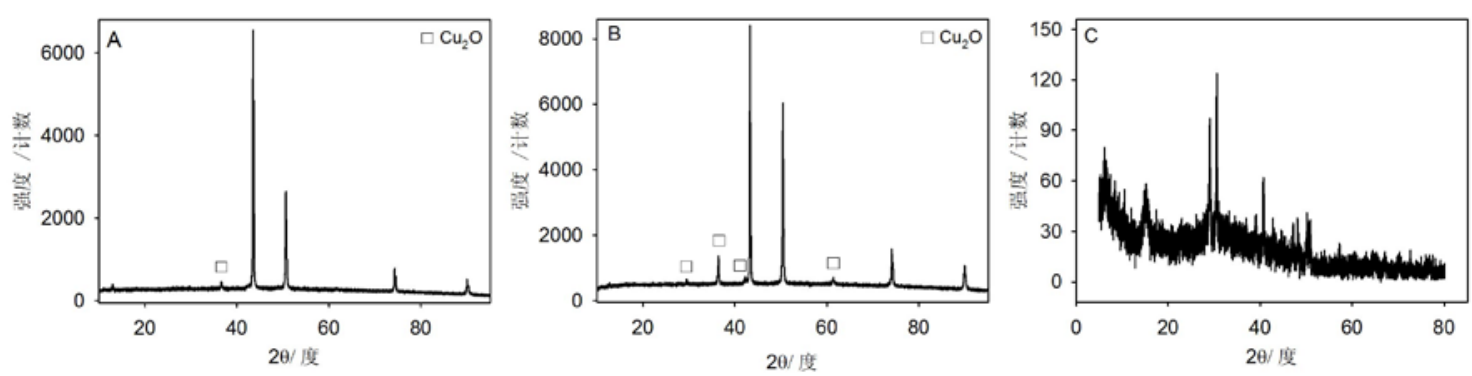

Fig. 5 Copper at different times after exposure XRD pattern. A: 3 months; B: 6 months; C: 12 months

We will expose the sample after the corrosion products formed with electrodes communicate impedance test, electrochemical impedance spectra obtained after fitting the data shown in Figure 6, Figure 6 is an equivalent circuit diagram inset corrosion of the electrode. An equivalent circuit diagram, Rs represents the resistance of the solution, Rct and Zw represent the charge transfer resistance and the concentration impedance. The electrode surface is rough due to corrosion, diffuse 
large, we use constant phase angle element Qdl to replace the electrode solution interface electric double layer. 7, the high end of the performance curve Nyquist real compression of capacitive arcs, high frequency capacitive arc reflecting electrode surface corrosion products on the electrodes during charge transfer resistance of the size of the [4,9]. As the exposure time extended from one month to 12 months, the high-frequency capacitive arc radius significantly increased corrosion products increased obstruction of the electrode process. This is due to the beginning of the exposed copper surface corrosion products shortly lighter, less corrosion products and loose impediment to smaller electrode process; with prolonged exposure time, increase the electrode surface corrosion products, thickening the copper surface a layer of relatively dense film, the corrosion of copper matrix diffusion media played a strong impediment resulting impedance increases.

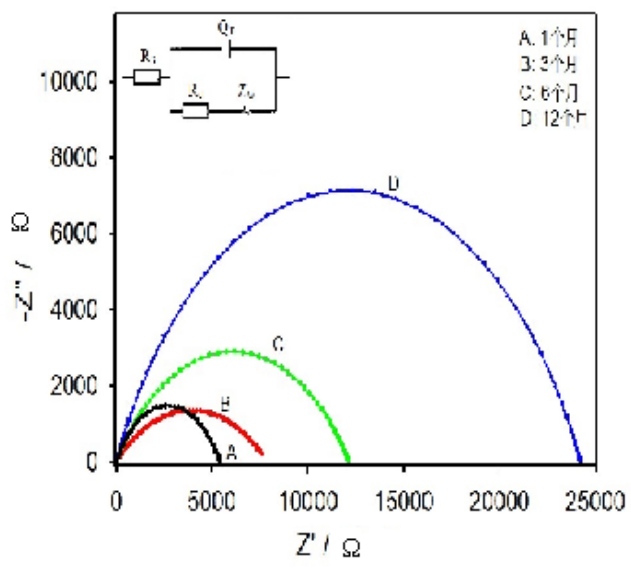

Fig. 6 Qingyuan copper exposure at different times of the impedance spectra, an equivalent circuit diagram of the inner illustrations

\section{Conclusion}

Copper exposure 1,3,6,9,12 months in Qingyuan rural atmosphere, the corrosion rate is significantly reduced with time. The major copper corrosion product is $\mathrm{Cu}_{2} \mathrm{O}$, after 12 months of exposure, corrosion material is $\mathrm{CuOHCl}$ product and $\mathrm{CuS}$.

AC impedance spectroscopy results showed that with prolonged exposure time, electrochemical impedance copper increases, the corrosion rate decreases. This is mainly due to the corrosion products gradually increased and more dense film is formed, slow the corrosion media intrusion and protect the copper substrate.

\section{Acknowledgements}

Guangdong Power Grid Corporation of Science and Technology Development Project No. L-GD 2013-0498002-002

\section{References}

[1] Z.Y. Wang, G.C. Yu. Atmospheric Corrosion of Copper in Polluted Environment. Corrosion and Protection, 2000, 21(8): 339-341.

[2] X. Zhang, Inger O W, Christofer L. Mechanistic Studies of Corrosion Product Flaking on Copper and Copper-Based Alloys in Marine Environments. Corrosion Science, 2014, 85(4): 15-25.

[3] Rosa V, Diana D, Blanca M R. Effect of Atmospheric Pollutants on The Corrosion of High Power Electrical Conductors-Part 2.Pure Coppoer. Corrosion Science, 2007, 49(6): 2329-2350.

[4] J. Wu, X.G. Li, C.F. Dong. Initial Corrosion Behavior of Copper and Brass in Tropical Maritime Atmospheric Environment. Journal of Chinese Society for Corrosion and Protection, 2012, 
32(1):70-74.

[5] M. Yang, Z.Y. Wang. Review of Atmospheric Corrosion of Copper. Equipment Environment Engineering, 2006, 3(4): 38-44.

[6] Fitzgerald K P, Nairn J, Skennerton G, Atrens A. Atmospheric Corrosion of Copper and The Colour, Structure and Composition of Natural Patinas on Copper. Corrosion Science, 2006, 48(9): 2480- 2509.

[7] Sandberg J, Wallinder I O, Leygraf C. Corrosion-Induced Copper Runoff from Naturally and Pre-Patinated Copper in A Marine Environment. Corrosion Science, 2006, 48(12): 4316-4338.

[8] B.G. Zhang, X.Y., E.H. Han. Corrosion Behavior of Pure Copper During Initial Exposure St An age in Atmosphere of Shenyang City. Acta Metallurgica Sinica, 2007, 43(1): 77- 81.

[9] C.N. Cao, J.Q. Zhang. Introduction to Electrochemical Impedance Spectroscopy. Beijing: Science Press, 2002. 